\title{
Medizin trifft Ökonomie
}

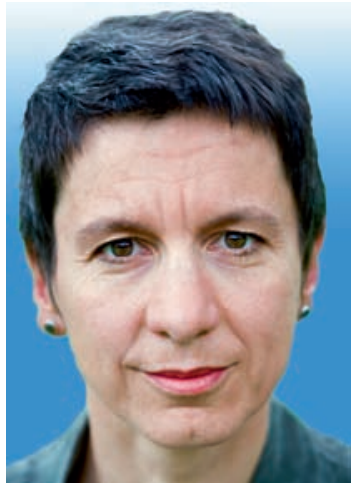

Anna Sax*
* Anna Sax, lic. oec. publ., MHA, Mitglied der Redaktion, ist Geschäftsführerin der Schweizerischen Gesellschaft für Gesundheitspolitik SGGP.
Ihre Zeitung, liebe Ärztinnen und Ärzte, interessiert nicht nur Sie, wie Sie bestimmt schon festgestellt haben. Wie viele andere Nichtärztinnen habe ich seit längerer Zeit regelmässig einen Blick ins «gelbe Blatt» geworfen, wobei ich meist hinten begann und mich unterschiedlich weit bis zu den FMH-Interna zurückarbeitete. Die Schweizerische Ärztezeitung ist eine gute Quelle, um zu erfahren, was die Medizinerinnen und Mediziner bewegt. Sie bringt spannende Diskussionsbeiträge $\mathrm{zu}$ medizinischen und gesundheitspolitischen Themen. Die inner- und interdisziplinären Debatten sind anregend, auch für Aussenstehende. Mein Ziel als frischgebackenes Redaktionsmitglied der SÄZ ist es, einen Beitrag vor allem an die interdisziplinäre Verständigung leisten zu können.

Als Ökonomin bekomme ich immer wieder zu hören, wie schädlich die «Verökonomisierung der Medizin» für die Gesundheitsversorgung sei. Diese Meinung teile ich dort, wo Ökonomie mit Sparmassnahmen und Rationierung gleichgesetzt wird. Hingegen halte ich es für sinnvoll, sich Gedanken über die Finanzierung des Gesundheitswesens zu machen und mehr Effizienz in der Mittelverteilung anzustreben. Nicht das Streben nach Kostensenkungen treibt mich als Gesundheitsökonomin um, sondern die Frage: Wie können wir mit den begrenzten Ressourcen, die uns zur Verfügung stehen, einen möglichst grossen Nutzen für die Allgemeinheit erzielen?

Seit Anfang der 90er Jahre habe ich mich beruflich aus verschiedenen Perspektiven mit Gesundheitspolitik auseinandergesetzt: Für meine früheren Arbeitgeber Erklärung von Bern, Sozialdemokratische Fraktion der Bundesversammlung und pro juventute stand jeweils die entwicklungs-, innen-, kinder- oder jugendpolitische Perspektive im Vordergrund. Bei der Schweizerischen Gesellschaft für Gesundheitspolitik SGGP, deren Geschäftsführerin ich seit 2004 im Hauptberuf bin, treffen nun endlich alle Sichtweisen aufeinander.

Besonders prägend für mein Verständnis von Interdisziplinarität war das Nachdiplomstudium
«Management im Gesundheitswesen» an der Universität Bern. Der ständige Austausch mit Angehörigen aller möglichen Gesundheitsberufe ist für mich seither zu einer Notwendigkeit für die berufliche Weiterentwicklung geworden. So habe ich gemeinsam mit vier Studienkollegen einem Ökonomen, zwei Ärzten und einem Juristen - eine Firma gegründet, deren Kapital hauptsächlich aus einem Netzwerk von Gesundheitsfachleuten aller Disziplinen besteht. Als Dozentin für Gesundheitsökonomie und -politik komme ich regelmässig mit Pflegefachpersonen und Angehörigen von therapeutischen Berufen in Kontakt.

Zum Glück gibt es immer mehr Ärztinnen und Ärzte, die sich mit den juristischen, wirtschaftlichen und gesellschaftlichen Auswirkungen ihres Tuns beschäftigen. Und es gibt Juristinnen, Ökonomen und Geisteswissenschaftlerinnen, die sich mit der Medizin auseinandersetzen. Je mehr sich die Disziplinen gegenseitig über den Gartenzaun blicken, desto mehr profitiert das Gesundheitswesen und damit auch die Gruppe, um die es eigentlich geht: die Patientinnen und Patienten. Wenn es gelingt, dass Politik, Leistungserbringer, Versicherungen, Industrie und Verbände eine bedürfnisorientierte Gesundheitsversorgung als ihre gemeinsame Aufgabe betrachten, dann sind wir einen grossen Schritt weiter.

Die Schweizerische Ärztezeitung ist und bleibt die Zeitung der Ärzteschaft. Als Ärztin oder Arzt werden Sie es aber in Zukunft vermehrt mit ökonomischen Fragestellungen zu tun bekommen. Das nehmen Sie hoffentlich nicht als Bedrohung wahr, sondern als spannende Herausforderung. Die Entwicklung hat sich in der SÄZ schon seit längerer Zeit gespiegelt, und sie wird jetzt sozusagen institutionalisiert, so wie es bereits mit der Ethik geschehen ist. Ich freue mich sehr auf meine künftige Aufgabe als Redaktionsmitglied und hoffe auf viele spannende, interdisziplinäre Auseinandersetzungen.

Anna Sax 